\title{
Essentialis thrombocythaemiás betegek kezelési eredményei osztályunkon
}

\author{
Iványi János László dr. - Marton Éva dr. \\ Plander Márk dr. - Szendrei Tamás dr. \\ Vas Megyei Markusovszky Kórház, Egyetemi Oktatókórház, Haematologiai és Haemostaseologiai Osztály, \\ Szombathely
}

\begin{abstract}
Bevezetés: Az essentialis thrombocythaemia a Philadelphia kromoszóma-negatív krónikus myeloproliferativ neoplasiák egyik entitása. A viszonylag hosszú kórlefolyás alatt a gyakori vérzés- és thrombosiskockázat thrombocytareduktív szerekkel (hidroxiurea, interferon, anagrelid) és aszpirinnel csökkenthető. Célkitüzés: A szerző́k előzetesen hidroxiureával kezelt, intolerancia/rezisztencia kialakulása miatt anagrelidre váltott vagy kiegészített essentialis thrombocythaemiás betegek klinikopatológiai és terápiás adatait és terápiás eredményeit dolgozták fel. Módszer: 2000 és 2014 között a hematológiai szakrendelésen kórismézett, első vonalban hidroxiureával kezelt 104 essentialis thrombocythaemiás betegnél (heti medián adag $7500 \mathrm{mg}$ ) intolerancia és/vagy rezisztencia esetén anagrelidre váltottak (heti medián dózis 7,5 mg), nem kielégítő monoterápiás válasz esetén a két szert egymással kombinálták. A kórlefolyás alatt rögzítették a vérzéses/thromboticus események és a mellékhatások számát. A statisztikai elemzést a Windows Statistical Software programmal végezték. Eredmények: A 104 essentialis thrombocythaemiás beteg (58 JAK2V617F-mutáció-pozitív, -negatív 46, calreticulinmutáció-negatív 15, MPL-1-mutáció-negatív 6) közül 87 beteg kapott első vonalban hidroxiureát, 4 beteg interferont, 13 beteg pedig csak acetilszalicilsavat. Hét hidroxiurea-intoleráns, illetve 22 hidroxiurea-rezisztens beteg kapott másodvonalban anagrelidet, közülük 18 beteg monoterápiában, 11 beteg hidroxiureával kombináltan, míg további 5, nagyrészt fiatal beteg első vonalban kapott anagrelidet $(34 / 104,32,6 \%)$. A primeren anagreliddel kezeltek mindegyike komplett remisszióba került, míg a másodvonalban anagreliddel kezelt csoportból 16, a hidroxiurea + anagrelid csoportból pedig 9 beteg került komplett remisszióba (100, 88,8 és 82,1\%). A 10 éves összesített túlélés $82,1 \%$ volt. Anagreliddel kezelt 2 betegnél vérzés, illetve egynél myocardialis infarctus következett be. A szerhez köthető más súlyos adverz eseményt nem észleltek. Három idős betegük hematológiai betegségtől független okok miatt elhunyt, leukaemiás transzformációt nem láttak. Következtetések: Essentialis thrombocythaemiás betegeikben az anagrelid első vagy másodvonalban, szükség esetén hidroxiureával kombinálva a klinikai kórlefolyást a thrombocytaszám csökkentésével kontrollálni képes, mellékhatásai általában tolerálhatók. Orv. Hetil., $2016,157(9), 336-341$.
\end{abstract}

Kulcsszavak: krónikus myeloproliferativ neoplasiák, essentialis thrombocythaemia, hidroxiurea, anagrelid

\section{Treatment outcome of patients with essential thrombocythemia in a single hematologic centre}

Introduction: Essential thrombocythemia is a Philadelphia chromosome-negative chronic myeloproliferative neoplasia with a risk of bleeding and thromboembolic complications during the course of illness. Cytoreductive drugs, such as non-selective hydroxyurea or interferon as first-line and specific, megakaryocyte-thrombocyte reductive anagrelide chosen as second-line treatment in cases of adverse, intolerable effects of hydroxyurea can lower the incidence of bleeding/thrombotic episodes in patients with essential thrombocythemia. Aim: In this observational survey the effect of anagrelide was investigated in patients with essential thrombocythemia, who were first treated with hydroxyurea but failed to have clinicopathologic reponse (resistant) or were intolerant (adverse effects). Method: Between 2000 and 2014, 104 patients were diagnosed with essential thrombocythemia and treated first-line with hydroxyurea (weekly median dose of $7500 \mathrm{mg}$ ) in the haematologic outpatient department of the authors. Because of intolerance and/or resistance, hydroxyurea was changed to anagrelide ( $7.5 \mathrm{mg}$ weekly median dose), the doses of hydroxyurea and anagrelide were adjusted to achieve clinicopathological response according to the updated criteria of the European LeukemiaNET. Effect of anagrelide as monotherapy (first- or second-line after hydroxyurea) or in combination with hydroxyurea was followed. Statistical analysis was performed using the Windows Statistical Package Program. Results: Of the 104 patients with essential thrombocythemia (according to the updated WHO-ET classifications 58 patients JAK2V617F mutation positive, 46 patients negative, 15 patients calreticulin mutation negative, 6 patients MPL-1 mutation negative) 87 patients received hydroxyurea in first line, 4 patients interferon, and 13 patients acetylsalycilic acid only. Seven patients who proved to be intolerant and 22 patients who were resistant to hydroxyurea 
received anagrelide in second line (in 18 patients monotherapy and in 11 patients in combination with hydroxyurea), while other 5 rather young patients in first line therapy $(34 / 104,32.6 \%)$. In the anagrelide first line group 5 patients $(100 \%)$, in the second line anagrelide monotherapy group 16 patients $(88,8 \%)$, and in the combined hydroxyurea plus anagrelide group 9 patients $(82.1 \%)$ achieved complete remission. The 10 -year overall survival was $82.1 \%$. In 2 patients treated with anagrelide major bleeding and in one patient myocardial infarction occurred, other serious adverse events due to anagrelide treatment were not detected. Three elder patients died from non-hematologic diseases, but leukaemic transformation was not observed. Conclusions: First or second line anagrelide therapy, combined with hydroxyurea if necessary, was able to reduce the platelet-count and the rate of complications, and to control the course of essential thrombocythemia with tolerable adverse effects.

Keywords: chronic myeloproliferative neoplasia, essential thrombocythemia, hydroxyurea, anagrelide

Iványi, J. L., Marton, É., Plander, M., Szendrei, T. [Treatment outcome of patients with essential thrombocythemia in a single hematologic centre]. Orv. Hetil., 2016, 157(9), 336-341.

(Beérkezett: 2015. november 9.; elfogadva: 2016. január 4.)

\section{Rövidítések}

ANAHYDRET $=$ anagrelide-hydroxyurea-essential thrombocythemia; bcr/abl = breakpoint cluster region/abelson leukemia; $\mathrm{cAMP}=$ ciklikus adenozin-monofoszfát $; \mathrm{CML}=$ krónikus myeloid leukaemia; $\mathrm{CR}=$ komplett remisszió; $\mathrm{ELN}=\mathrm{Eu}-$ ropean Leukemia Network; ET = essentialis thrombocythaemia; $\mathrm{HU}=$ hidroxiurea, -karbamid; IFN = interferon; IPSET = International Prognostic Score of thrombosis in essential thrombocythaemia; JAK = Janus-arcú kináz; MDS = primer myelodysplasiás szindróma; MPL-1 = myeloproliferativ leukaemia vírus; $\mathrm{MVT} / \mathrm{PE}=$ mélyvénás thrombosis $/$ pulmonalis $\mathrm{em}$ bolia; $\mathrm{OS}=$ összesített (overall) túlélés; $\mathrm{PR}=$ részleges $/$ parciális remisszió; $\mathrm{PV}=$ polycytaemia vera $; \mathrm{PVSG}=$ Polycytemia Vera Study Group; TIA = tranzitorikus ischaemiás attak; WHO $=$ (World Health Organization) Egészségügyi Világszervezet

Az essentialis (primer) thrombocythaemia (ET) a Philadelphia kromoszóma-negatív krónikus myeloproliferativ betegségek/neoplasiák egyik betegsége, minden életkorban, mindkét nemben előforduló entitás. Az újabb molekuláris biológiai és korszerü immunhisztokémiai adatok és laboratóriumi, klinikai paraméterei alapján fó jellemzője a csontvelőben a megakaryocyta-vonal klonális proliferációja, a perifériás vérképben a $450 \times 109$ /L-t meghaladó thrombocytaszámmal [1-3]. Az esetek körülbelül 60\%-ában kimutatható a JAK2V617F-mutáció, 30\%-ában calreticulin- és 3\%-ában MPL- (myeloproliferativ leukaemia vírus oncogen) -mutáció, amelyek jelenléte tovább finomíthatja az ET egyes altípusainak jellegzetességeit $[4,5]$. Postessentialis myelofibrosis és leukaemiás átalakulás ebben az entitásban viszonylag ritkán fordul elő. A hosszú kórlefolyás alatt - ellentétben a szekunder thrombocytosissal - a makro-, mikrocirkulációs zavarok előfordulása, vérzés és esetenként fatális artériás/vénás thrombosis kifejezett kockázatával jár, gondos rizikóstátusz felmérése (idősek, tünetek, korábbi thrombosis) után thrombocytaszámot redukáló szisztémás kezeléssel és kis dózisú acetilszalicilsavval a thromboticus rizikó csökkenthető $[6,7]$.
Az ET (és polycytaemia vera - PV) kezelésében több évtizede forgalomban levő cytoreductiv szerek (hidroxiurea, -karbamid, HU, interferon, anagrelid, busulphan, korábban pipobroman, $\mathrm{P}^{32}$ ) közül első vonalban a $\mathrm{HU}$ terjedt el általánosan és törzskönyvezett hazánkban is, emellett az alfa-interferon - tolerálhatóbb formában pegilált interferon - IFN és másodvonalban anagrelid, fóként HU-refrakter és -intoleráns esetekben ajánlott [8-10]. Önállóan vagy kiegészítő szerként kis dózisban (100 mg/nap) adott aszpirintől először PV-ben, később az ET-ben a thrombosiskockázat csökkenése tapasztalható [11]. A HU a sejt DNS-szintézisébe avatkozik bele a ribonukleotid-reduktáz gátlása révén. A hosszan tartó HU-terápia (ajánlott kezdő adag $15 \mathrm{mg} / \mathrm{kg} / \mathrm{nap}$ ) lényeges mellékhatása myeloszuppresszión és ulcus cruris kialakulásán kívül az egyébként ténylegesen nem bizonyított leukemogén volta, ezért elsősorban fiatal ET-s betegekben fokozott óvatosság miatt IFN vagy anagrelid a választandó készítmény [12]. Az éveken át tartó HUkezelés alatt a betegek mintegy 25\%-ánál HU-rezisztencia alakul ki, amely maximális dózissal sem kontrollálható, emellett a betegek változó arányában $\mathrm{HU}$-intolerancia lép fel (nem befolyásolható myeloszuppresszió, refrakter thrombocytosis, változatos bő́rlaesiók, perifériás polyneuropathia, vesekárosodás) [13].

$\mathrm{Az}$ anagrelid egy imidazoquinolin-származék, amely szelektíven gátolja az érési stádiumban levő megakaryopoesist és a thrombocytalefüződést, emellett gátolja a vérlemezkék III. típusú foszfodiészterázaktivitását, és így a cAMP-szint növekedésével az aggregációgátlás is fokozódik, aszpirinnel együtt adva szerzett von Willebrandállapot következhet be vérzésveszéllyel. Az anagrelidről (kezdő adag általában $1 \times 0,5 \mathrm{mg} / \mathrm{nap}$, maximum $5 \mathrm{mg}$ / nap) nem írtak le leukemogén hatást, kardiális (palpitatio), gastrointestinalis (hányás, hasmenés) mellékhatásai általában enyhék, szelektív thrombocytaszám-csökkentő hatása miatt pancytopenia általában nem alakul ki, s carcinogen hatást sem bizonyítottak [14, 15]. Az elmúlt évtizedben végzett $\mathrm{HU}$-anagrelid összehasonlító hatástanulmányok (vénás thrombosis előfordulása, tolerabili- 
1. táblázat $\quad \mathrm{Az}$ essentialis thrombocythaemia diagnosztikai kritériumai (WHO 2008)

1. Thrombocytaszám tartósan $\geq 450 \times 10^{9} / \mathrm{L}$.

2. Csontvelő-biopsziában érett-megnagyobbodott megakaryocytákból álló proliferatio, normál erythro- és granulopoesis.

3. Egyéb myeloid neoplasiák kizárása (bcr/abl pozitív CML, PV, primer myelofibrosis, MDS).

4. JAK2V617F vagy egyéb klonális marker megléte, JAK2V617F hiánya esetén reaktív thrombocytosis kizárása.

Mind a négy kritérium együttes jelenléte szükséges az ET kórisméjéhez.

2. táblázat | IPSET kockázati csoportok essentialis thrombocythaemiában

\begin{tabular}{|c|c|c|}
\hline \multicolumn{3}{|c|}{ Prognosztikai faktorok essentialis thrombocythaemiában } \\
\hline Életkor & $>60$ év & (2 pont) \\
\hline \multicolumn{2}{|c|}{ Elözetesen lezajlott thrombosis } & (1 pont) \\
\hline Leukocytosis & $>11 \times 10^{9} / \mathrm{L}$ & (1 pont) \\
\hline \multicolumn{3}{|c|}{ Kockázati csoportok } \\
\hline \multicolumn{3}{|c|}{ kis kockázatú } \\
\hline \multicolumn{3}{|c|}{ intermedier kockázatú } \\
\hline 3-4: nagy $k$ & \multicolumn{2}{|c|}{ nagy kockázatú } \\
\hline
\end{tabular}

tás, fiatal nők, idős betegek) az anagrelidet non-inferiornak, HU-nál nem rosszabbnak hozták ki (ANAHYDRET, EXELS tanulmány). Monoterápiás kudarcok esetén a két szer kis adagú kombinálása kedvező terápiás választ eredményezhet [16-19].

Tizenöt évet átfogó felmérésünkben hematológiai osztályunkon/szakambulanciánkon kórismézett, kezelt, gondozott essentialis thrombocythaemiás betegeink klinikopatológiai adatait, a terápia módozatait, eredményességét mértük fel s kívánjuk közreadni.

\section{Betegek és módszer}

A Vas Megyei Markusovszky Kórház Haematologiai és Haemostaseologiai Osztályán és Szakambulanciáján 2000. január 1. és 2014. december 31. között thrombocytosis miatt vizsgált betegeink közül 115 betegben igazoltunk primer/essentialis thrombocythaemiát, közülük 104 beteget vontunk be felmérésünkbe. A kórismét a PVSG, majd a WHO 2008 diagnosztikai kritériumai alapján állítottuk fel (Ph-kromoszóma kizárása, csontvelő szövettani vizsgálata), illetve 2004-től molekuláris biológiai analízissel (bcr/abl fúziós gén, JAK2617F-mutáció, 2013-tól calreticulin és MPL-1-mutáció kimutatása) egészítettük ki, a vizsgálati mintákat a Pécsi Tudományegyetem Pathologiai Intézete, Citogenetikai és Molekuláris Biológiai Laboratórium és a Semmelweis Egyetem, I. Patológiai Intézet Molekuláris Biológiai Laboratóriuma, illetve az Országos Vérellátó Szolgálat Központi La- boratóriuma dolgozta fel [5]. A WHO 2008-as diagnosztikai kritériumait mutatja be az 1. táblázat [20].

Kizártuk az egyéb thrombocytosissal járó állapotokat, kórképeket (szekunder thrombocytosis, krónikus myeloproliferativ betegségek, úgymint: krónikus myeloid leukaemia, Ph-kromoszóma-negatív egyéb krónikus myeloproliferativ betegségek, myelodysplasiás szindróma/ MDS-RARS thrombocytosissal). Rögzítettük a betegek belgyógyászati és hematológiai státuszát, életkorát, mikro- és makrocirkulációs tüneteit, előzményeit (cardio- és cerebrovascularis szövődmények), élvezeti szokásait, hematológiai paramétereit (haemostatus, lépméret). 2000 és 2012 között az akkori ajánlások szerint indítottunk cytoreductiv kezelést (60 év feletti életkor, 1000 G/L feletti thrombocytaszám, vérzéses-thromboticus előzmények), rögzítettük a cardiovascularis rizikófaktorok, úgymint: hypertonia, diabetes mellitus, hypercholesterinaemia, dohányzás meglétét [6, 20], 2012-től az IPSET-pontrendszer alapján felállított rizikócsoportoknak megfelelően (3-4. pont, high risk) [21] (2. táblázat).

\section{Kezelés}

A fentiek alapján a 15 éves megfigyelési időszak alatt bevont 104 beteg közül 13 beteg stabil mérsékelt thrombocytosis és egyéb kockázati tényezők híján csak kis dózisú (100 mg naponta) acetilszalicilsavat kapott, négy fiatal beteg, köztük egy gravida alfa-interferont (interferon-alfa- $2 \mathrm{a}$, interferon-alfa- $2 \mathrm{~b}$, Intron-A, Roferon átlagosan heti $3 \times 3 \mathrm{MUI})$, míg 87 betegnél első vonalban hidroxiureát indítottunk (Litalir), haemostatusparaméterektől függően $10-15 \mathrm{mg} / \mathrm{kg} /$ nap kezdő adagban, amelyet szükség esetén módosítottunk. Az anagrelid (Xagrid, hazánkban nem hozzáférhető, Thromboreductin) indikációja legtöbbször HU rezisztencia/intolerancia volt (másodvonalbeli kezelés) 29 betegnél, míg öt beteg primeren kapott anagrelidet (fiatal, nem kívánt potenciálisan leukemogen szert szedni), a kezdő adag napi $1 \times 0,5 \mathrm{mg}$ volt, amelyet szükség esetén átlag kéthetente növeltünk (maximális adag $5,0 \mathrm{mg}$ ).

A terápiás választ a klinikai tünetek enyhülése, a thrombocyta- és leukocytaszám normalizálódása, normális lépméret alapján mértük fel (komplett, parciális válasz és nonreszponder, ELN-kritériumok) [22] (3. táblázat).

A HU-rezisztenciát fél éves kezelésre adott elégtelen válasz (lényegében nem normalizálódó thrombocytaszám), a HU-intoleranciát anaemizálódás, tartósan fennálló, tüneti szerekre nem javuló gastrointestinalis, illetve cardiovascularis tünetek és legtöbbször bőrlaesiók (vasculitis, fekélyek, seborrhoeás elváltozások, tumorok) megjelenése kapcsán mondtuk ki. A cytoreductiv terápia alatt kialakuló thrombosist/vérzést az adott szer súlyos szövődményeként értékeltük. Kombinált kezelést (HU visszaépítése) anagrelid mellett észlelt parciális válasz vagy emelt adag melletti intolerancia, mellékhatások megjelenése (szívelégtelenség, palpitatio, fejfájás, dep- 
3. táblázat Klinikohematológiai terápiás válasz essentialis thrombocythae miában (ELN-kategóriák)

\begin{tabular}{ll}
\hline Remisszió & Definíció \\
\hline Komplett $(\mathrm{CR})$ & 1. vérlemezkeszám $\leq 400 \times 10^{9} / \mathrm{L}$ \\
& $\begin{array}{l}\text { 2. normál lépméret }(\mathrm{UH}, \mathrm{CT}, \mathrm{MR}) \\
\text { 3. betegségtünetek nincsenek } \\
\\
\text { 4. fehérvérsejtszám } \leq 10 \times 10^{9} / \mathrm{L}\end{array}$ \\
Részleges (partialis/PR) & $\begin{array}{l}\text { 1. vérlemezkeszám } \leq 600 \times 10^{9} / \mathrm{L}, \\
\text { a csökkenés mértéke }>50 \%-\mathrm{a}\end{array}$ \\
& a kiindulási értéknek \\
\hline $\begin{array}{l}\text { Nem reagáló } \\
\text { (nonreszponder) }\end{array}$ & $\begin{array}{l}\text { bármilyen csökkenés, amely nem felel } \\
\text { meg a PR feltételeinek }\end{array}$ \\
\hline
\end{tabular}

resszió) és vérképkorrekció szükségessége miatt állítottunk be, a két szer adagjának óvatos titrálásával a thrombocytaszám normalizálódásáig. Relapsus, terápiás válasz elvesztése egy hónapos különbséggel mért két egyező, normálértéket meghaladó vérlemezkeszám esetén következett be. A cytoreductiv szerek mellé kiegészítésként a thrombocytaszám rendeződéséig acetilszalicilsavat építettünk be, extrém magas thrombocytosis $\left(>1500 \times 10^{9} / \mathrm{L}\right)$ esetén szerzett von Willebrand-betegség, vérzés kockázata miatt azt a vérlemezkeszám csökkenéséig prolongáltuk.

\section{Statisztikai analizis}

A követési időszak alatt a klinikai végpontok közül a vénás-artériás thrombosis, vérzés megjelenése, a betegség leukaemiás transzformációja, szekunder malignoma megjelenése és a beteg kiválása (halálozás) szerepeltek statisztikai tényezőként, az összesített túlélést a KaplanMeier-módszer alapján állítottuk össze. A számításokat a Windows Statistical Software Program felhasználásával végeztük el.

\section{Eredmények}

2000. január 1. és 2014. december 31. között 104 essentialis thrombocythaemiás beteget észleltünk hematológiai szakambulanciánkon, akik a 180 hónapos obszervációs időszak alatt (4-180, medián 138 hónap) betegségük miatt kezelésben részesültek. A 42 férfi és 62 nőbeteg (40,3\% és 59,7\%) átlagéletkora 53,5 (16-89, medián 52) év volt. Ezen időszak alatt három beteg hunyt el nem hematológiai betegség miatt $(2,8 \%)$. A betegek ambuláns adatlapjaiból és kórházi felvételkor felvett kórlapokból nyert adatok közül vizsgáltuk a JAK2V617F-mutáció, utóbbi években a calreticulin- és MPL-1-mutáció előfordulását, az ET-t megelőzően vagy a kórlefolyás alatt észlelt thrombosis/vérzés bekövetkeztét, a kezelés megoszlását és a terápiás válasz minőségét. Első vonalban 87 beteget kezeltünk hidroxiureával (medián 126, 2-162 hónap), közülük 61 került tartósan komplett remisszióba, míg 29 betegnél kórlefolyásuk alatt kialakult intole- rancia ( 7 beteg), rezisztencia ( 22 beteg), azaz a komplett remisszió elvesztése miatt másodvonalbeli kezelés vált szükségessé $(29 / 87,33,3 \%)$. Az anagrelidterápia időtartama medián 51 hó (4-66). Ezek a betegek vagy monoterápiában kaptak anagrelidet (18 beteg), vagy részleges terápiás válasz miatt $\mathrm{HU}$ + anagrelid kombinációra kényszerültünk ( 11 beteg). Előbbi csoportból 16 beteg jutott komplett remisszióba, míg az utóbbiból 9 betegnél értünk el komplett választ (CR 88,8, illetve 82,1\%). Az interferonnal kezelt négy és az első vonalban anagreliddel kezelt öt betegnél is évek óta tartós terápiás válasz áll fenn. A 10 éves összesített túlélés 82,1\%. Molekuláris genetikai vizsgálatokra (JAK2V617F-, calreticulin- és MPLmutáció) az elmúlt évtized közepétől van lehetőségünk, újonnan kórismézetteknél, illetve korábbról kezelteknél rendszeresen felmérjük-kiegészítjük molekuláris genetikai státuszukat. JAK2V617F-mutációt 58 betegnél igazoltunk $(58 / 104,55,7 \%)$, nem mutált állapot 46-nál fordult elő, ezeknél folyamatosan calreticulin- és MPLmutáció-szűrés történik [5].

Thromboticus/vérzéses szövődmények (kórisme felállítása előtt, kórlefolyás alatt) közül nehezen befolyásolható vérzés két, akut myocardialis infarctus egy (mindhárom) anagreliddel kezelt betegben fordult elő, míg cardiovascularis thromboticus előzmény (ritmuszavar, angina pectoris, myocardialis infarctus) kilenc, vénás thrombosis öt, cerebrovascularis esemény (TIA, stroke) 14 esetben indította el a thrombocytosis hátterének kivizsgálását. Betegeink klinikopatológiai jellemzőit és a kezelésre adott választ a 4. táblázatban foglaljuk össze. A 10 éves összesített túlélés (OS) 82,1\% volt, a két szerrel kezeltek túlélése között szignifikáns különbség nem mutatkozott (100,0\%, illetve 88,8\%) (4. táblázat).

\section{Megbeszélés}

Az essentialis thrombocythaemia a Philadelphia kromoszóma-negatív krónikus myeloproliferativ neoplasiák egyik viszonylag benignus, több évtizedes hosszú kórlefolyású, tüneteket kezdetben alig okozó betegsége, amelyre az esetek közel 50\%-ában véletlenül felfedezett thrombocytosis, esetleg mikrocirkulációs tünetek vagy - súlyosabb helyzetekben - artériás-vénás macrovascularis keringészavarok (myocardialis infarctus, stroke vagy pulmonalis embolia) bekövetkezte után derül fény. A kórisme felállításának szokványos haemostatusparamétereken túl előfeltétele a Philadelphia kromoszóma kizárása rutin és molekuláris citogenetikai analízissel (krónikus myeloid leukaemia) és a csontvelő hisztológiai vizsgálata, amely döntóen a megakaryocyták jellegzetes morfológiáján, velőűrbeli megoszlásán alapul, és segít elkülöníteni egyéb myeloproliferativ kórképektől (PV, primer myelofibrosis és ennek praefibroticus stádiuma) [23]. Újabb molekuláris citogenetikai paraméterek (calreticulin-, MPL-mutáció) egyes ET-alcsoportok prognosztikai megítélését teszik lehetővé $[4,5]$. 
4. táblázat $\mid$ Essentialis thrombocythaemiás betegek klinikopatológiai adatai és a kezelés eredményei

\begin{tabular}{ll}
\hline Essentialis thrombocythaemia & $\mathrm{n}=104$ \\
$\quad$ férfi & $\mathrm{n}=42$ \\
$\quad$ nö & $\mathrm{n}=62$ \\
Életkor (medián) & $52(16-89)$ év \\
Előzetes thrombosis & \\
$\quad$ cardiovascularis & $\mathrm{n}=9$ \\
$\quad$ cerebrovascularis & $\mathrm{n}=13$ \\
mikrocirkuláció & $\mathrm{n}=62$ \\
mélyvénás thrombosis/pulmonalis embolia & $\mathrm{n}=5$ \\
Elözetes vérzés & $\mathrm{n}=0$ \\
Cardiovascularis kockázati tényezők & $\mathrm{n}=61$ \\
\hline
\end{tabular}

\begin{tabular}{lll}
\hline JAK2V617F-mutáció & calreticulinmutáció & $M P L-1$-mutáció \\
\hline pozitív 58 & & \\
negatív 46 & negatív 15 & negatív 6
\end{tabular}

Aszpirin $\quad n=13$

\begin{tabular}{lcl}
\hline Kezelés & Betegszám & Terápiás válasz \\
\hline IFN & 4 & CR 4 \\
Elsö vonal & & \\
HU & 87 & CR 61 \\
Anagrelid & 5 & CR 5 \\
Másodvonal & 29 & \\
$\quad$ HU-intolerancia & 7 & \\
HU-rezisztencia & 22 & \\
Anagrelid & 18 & CR 16 \\
HU + Anagrelid & 11 & CR 9 \\
\hline
\end{tabular}

A kórlefolyást, az életminőséget elsősorban a keringési szövődmények előfordulása befolyásolhatja leginkább, s az esetenként fatális vérzés, thrombosis (ET-ben inkább artériás) megelőzése miatt szükséges az ET-s betegek gondozása és egyes rizikócsoportok kezelése. Fő terápiás cél a thrombocytaszám elsődleges csökkentése, normalizálása cytoreductiv szerekkel a kóros haemostasis rekonstitutióját, a fokozott thrombocytaaggregáció csökkenését, a vérlemezkék foszfodiészteráz-aktivitásának gátlását okozva hivatott mind a vérzés, mind a thrombosis kockázatát csökkenteni. Német-osztrák ajánlás kis molekulatömegű heparinprofilaxist javasol 3-6 hónapon keresztül nagy thrombosiskockázat esetén [24]. A cytoreductiv készítmények (hidroxiurea, anagrelid, interferon) több évtizede ismertek a myeloproliferativ betegségek kezelésében, terápiás hasznuk mellett súlyos mellékhatásaik (a HU potenciálisan leukemogen lehet, bár nem bizonyított) miatt meg kell határozni az okvetlenül kezelendők csoportját (nagy thrombosiskockázat). Az utóbbi két évtized alatt különböző munkacsoportok által sta- tisztikai vizsgálatokkal alátámasztott kockázati tényezők rangsorolása nagyrészt egybehangzó, az IPSET-pontrendszer hazai munkacsoport vizsgálata alapján is jól alkalmazható thrombosiskockázat megítélésére [25]. A 65 év feletti életkor, előzetes thrombosis azonnali kezelést igényel, thrombogen (cardiovascularis rizikótényezők) megléte, nagy tumortömeg $\left(1000 \times 10^{9} / \mathrm{L}\right.$ feletti vérlemezkeszám) esetén kockázat-előny mérlegelésével indítható kis dózisú acetilszalicilsav mellé thrombocytaszám-csökkentő terápia. A nemzetközi ajánlásoknak megfelelően hazánkban is az első vonalban választandó HU van törzskönyvezve. Speciális helyzetekben (terhesség) a nem leukemogen, nem teratogén pegilált interferon javasolt. Az anagrelidet mellékhatásai és egyes felmérésekben gyakoribb thrombosis-előfordulás miatt sokáig a HU-nál gyengébbnek tartották [16], az ANAHYDRET tanulmány szerint hatása, a szövődmények előfordulása és mellékhatásainak mértéke alapján nem rosszabb az összehasonlított HU-nál, nagy előnye szelektivitása és nem leukemogen volta, ezért fiatal betegek éveken keresztüli kezelésére alkalmasabbnak látszik [17]. Az újabb JAK-inhibitorokról (ruxolitinib, pacritinib), telomerázbénítókról ET-ben egyelőre kevés adat áll rendelkezésre.

15 évet átfogó felmérésünkben a fentebb írtak tükröződnek vissza, a 104 ET-s beteg (női dominancia, középkorú átlag ellenére minden életkort érintő) klinikai jellemzői közül a hosszú kórlefolyás, alacsony mortalitás, a kezeletlen betegek 1/4-ében előforduló megelőző thromboticus események $(28 / 104,26,9 \%)$ nagyrészt megfelelnek az egyes munkacsoportok által közölteknek. A kedvező túlélés elsősorban a betegség nem aggresszív jellegével magyarázható, de a vascularis szövődmények (stroke, myocardialis infarctus) az életminőséget súlyosan ronthatják. A thrombocytosis első észlelését nem mindig követi ezen betegek közeli hematológiai kivizsgálása. A cytoreductiv terápia ténylegesen profilaktikus, az újabb vascularis események megelőzését szolgálja. Betegeinkben mindhárom szer (az interferon is) bevált, bár három, anagreliddel már kezelt betegben vérzést, illetve artériás thrombosist tapasztaltunk normális thrombocytaszám és -aggregációgátló kezelés ellenére. A hidroxiureáról csak intolerancia/rezisztencia esetén tértünk át anagrelidre, de annak parciális hatása esetén újból beépítve a kombinált kezeléstől kedvező választ láttunk, együttes adása azonban myeloszuppresszió fokozott kockázatát hordozza. Az anagrelid első vonalbeli kezelését hazai elóírások nem támogatják, pedig bizonyos ETcsoportokban (fiatalok) magunk és más munkacsoportok szerint is a HU-val egyenértékü. Molekuláris biológiai vizsgálatokat rendszeresen végeztetünk a megjelölt intézményekben, egyelőre a JAK2-mutációt hordozó betegekről van értékelhető adatunk, a pozitív és nem mutált (JAK-negatív) esetek és a regisztrált thrombosisok közel azonos száma alapján a mutáció meglétét ET-ben nem tartjuk szignifikáns tényezőnek. Hazai felmérés sem talált direkt összefüggést a thrombosis és a fenti mutációk jelenléte vagy hiánya között [25]. A 3 
mutáció eredményeinek feldolgozása, gyűjtése folyamatos, értékelésük újabb alcsoportokra deríthet fényt (MPL-1-mutációt hordozókban rövidebb túlélést találtak) esetleg más terápiás konzekvenciával.

Anyagi támogatás: A közlemény megírása anyagi támogatásban nem részesült.

Szerzői munkamegosztás: I. J. L.: Az adatok feldolgozása, a kézirat megszerkesztése. M. É., P. M., Sz. T.: A kézirat végleges összeállítása. Mind a négy szerző részt vett a betegek gondozásában, kezelésében, a betegadatok öszszegyűjtésében. A cikk végleges változatát valamennyi szerző elolvasta és jóváhagyta.

\section{Érdekeltségek: A szerzőknek nincsenek érdekeltségeik}

\section{Köszönetnyilvánítás}

A szerzők köszönettel tartoznak a Pécsi Tudományegyetem, Általános Orvostudományi Kar Pathologiai Intézete (igazgató: Dr. Pajor László egyetemi tanár), a Semmelweis Egyetem, Általános Orvostudományi Kar I. Patológiai Intézete (igazgató: Dr. Matolcsy András egyetemi tanár) és az Országos Vérellátó Szolgálat Központi Laboratóriuma (laborvezető: Dr. Andrikovics Hajnalka) munkatársainak a cristabiopsziák leletezéséért, a rutin citogenetikai és molekuláris biológiai vizsgálatok elvégzéséért és a leletek rendelkezésre bocsátásáért.

\section{Irodalom}

[1] Michiels, J. J., De Raeve, H., Berneman, Z., et al.: The 2001 World Health Organization and updated European clinical and pathological criteria for the diagnosis, classification, and staging of the Philadelphia chromosome-negative chronic myeloproliferative disorders. Semin. Thromb. Hemost., 2006, 32(4), 307340 .

[2] Tefferi, A.: Polycythemia vera and essential thrombocythemia: 2013 update on diagnosis, risk-stratification, and management. Am. J. Hematol., 2013, 88(6), 507-516.

[3] Tefferi, A., Barbui, T.: Polycythemia vera and essential thrombocythemia: 2015 update on diagnosis, risk-stratification and management. Am. J. Hematol., 2015, 90(2), 162-173.

[4] Tefferi, A., Wassie, E. A., Lasho, T. L., et al.: Calreticulin mutations and long-term survival in essential thrombocythemia. Leukemia, 2014, 28(12), 2300-2303.

[5] Andrikovics, H., Krähling, T., Balassa, K., et al.: Distinct clinica characteristics of myeloproliferative neoplasms with calreticulin mutations. Haematologica, 2014, 99(7), 1184-1190.

[6] Finazzi, G., Barbui, T.: Risk-adapted therapy in essential thrombocythemia and polycythemia vera. Blood Rev., 2005, 19(5), 243-252.

[7] Gowin, K., Mesa, R.: Management of thrombocythemia F1000Res., 2014, 3, 227

[8] Barbui, T., Finazzi, M. C., Finazzi, G.: Front-line therapy in polycythemia vera and essential thrombocythemia. Blood Rev., 2012, 26(5), 205-211.

[9] Sever, M., Newberry, K. J., Verstovsek, S.: Therapeutic options for patients with polycythemia vera and essential thrombocythemia refractory/resistant to hydroxyurea. Leuk. Lymphoma, 2014, 55(12), 2685-2690.

[10] Kiladjian, J. J., Rain, J. D., Bernard, J. F., et al.: Long-term incidence of hematological evolution in three French prospective studies of hydroxyurea and pipobroman in polycythemia vera and essential thrombocythemia. Semin. Thromb. Hemost., 2006, 32(4), 417-421.

[11] Patrono, C., Rocca, B., De Stefano, V.: Platelet activation and inhibition in polycythemia vera and essential thrombocythemia. Blood, 2013, 121(11), 1701-1711.

[12] Tefferi, A.: Is hydroxyurea leukemogenic in essential thrombocythemia? Blood, 1998, 92(4), 1459-1460.

[13] Rey, J., Viallard, J. F., Keddad, K., et al.: Characterization of different regimens for initiating anagrelide in patients with essential thrombocythemia who are intolerant or refractory to their current cytoreductive therapy: results from the multicenter FOX study of 177 patients in France. Eur. J. Haematol., 2014, 92(2), 127-136.

[14] Petrides, P. E., Gisslinger, H., Steurer, M., et al.: Pharmakokinetics, bioequivalence, tolerability, and effects on platelet counts of two formulations of anagrelide in healthy volunteers and patients with thrombocythemia associated with chronic myeloproliferation. Clin. Ther., 2009, 31(2), 386-398.

[15] Emadi, A., Spivak, J. L.: Anagrelide: 20 years later. Expert Rev. Anticancer Ther., 2009, $9(1), 37-50$.

[16] Harrison, C. N., Campbell, P. J., Buck, G., et al.: Hydroxyurea compared with anagrelide in high-risk essential thrombocythemia. N. Engl. J. Med., 2005, 353(1), 33-45.

[17] Gisslinger, H., Gotic, M., Holowiecki, J., et al.: Anagrelide compared with hydroxyurea in WHO-classified essential thrombocythemia: the ANAHYDRET Study, a randomized controlled trial. Blood, 2013, 121(10), 1720-1728.

[18] Kiladjian, J. J., Besses, C., Griesshammer, M., et al.: Efficacy and safety of cytoreductive therapies in patients with essential thrombocythaemia aged $>80$ years: an interim analysis of the EXELS study. Clin. Drug Investig., 2013, 33(1), 55-63.

[19] Squizzato, A., Romualdi, E., Passamonti, F., et al.: Antiplatelet drugs for polycythaemia vera and essential thrombocythaemia. Cochrane Database Syst. Rev., 2013, (4), CD006503.

[20] Barosi, G., Birgegard, G., Finazzi, G., et al.: Response criteria for essential thrombocythemia and polycythemia vera: result of a European LeukemiaNet consensus conference. Blood, 2009, $113(20), 4829-4833$.

[21] Barbui, T., Finazzi, G., Carobbio, A., et al.: Development and validation of an International Prognostic Score of thrombosis in World Health Organization-essential thrombocythemia (IPSETthrombosis). Blood, 2012, 120(26), 5128-5133.

[22] Hernández-Boluda, J. C., Pereira, A., Cervantes, F., et al.: Clinical evaluation of the European Leukemia Net response criteria in patients with essential thrombocythemia treated with anagrelide. Ann. Hematol., 2013, 92(6), 771-775.

[23] Schmitt-Graeff, A. H.: Chronic myeloid neoplasms. Diagnostic criteria and current therapeutic concepts. [Chronische myeloische Neoplasien. Diagnostische Kriterien und Ausblick auf aktuelle Theapiekonzepte.] Pathologe, 2010, 31(1), 29-41. [German]

[24] Kreher, S., Ochsenveither, S., Trappe, R. U., et al.: Prophylaxis and management of venous thromboembolism in patients with myeloproliferative neoplasms: consensus statement of the Haemostasis Working Party of the German Society of Hematology and Oncology (DGHO), the Austrian Society of Hematology and Oncology (ÖGHO) and Society of Thrombosis and Haemostasis Research (GTH e.V.). Ann. Hematol., 2014, 93(12), 19531963.

[25] Pósfai, É., Marton, I., Király, P. A., et al.: JAK2 V617F, MPL, and CALR mutations in essential thrombocythaemia and major thrombotic complications: a single-institute retrospective analysis. Pathol. Oncol. Res., 2015, 21(3), 751-758.

(Iványi János László dr., Szombathely, Markusovszky L. u. 5., 9700 e-mail: jlivanyi@freemail.hu) 